\title{
Os gêneros textuais e o vestibular da UEM: entre o que é prescrito nos documentos oficiais e o que é cobrado dos candidatos
}

Los géneros textuales y el examen de ingreso de la UEM: entre lo que es prescrito en los documentos oficiales y lo que es evaluado en los candidatos

The textual genres and the university entrance examination of UEM: between what is prescribed in the official documents and what is charged of the candidates

Nayara Maira da Silva ${ }^{1}$

Elvira Lopes Nascimento ${ }^{2}$

\begin{abstract}
RESUMO: Este trabalho tem como objetivo investigar a relação entre o que é prescrito nos documentos oficiais e o que é cobrado no vestibular da UEM, a fim de observar se há ou não regularidade nos gêneros selecionados para a prova. Trata-se de uma pesquisa qualitativa, na qual foram analisadas as questões de Língua Portuguesa e a proposta de redação de duas edições do vestibular de verão da UEM (2016 e 2017). Em seguida, foram realizadas entrevistas com duas professoras de língua portuguesa do ensino médio, uma da rede pública de ensino e outra da rede particular, visando verificar se consideram as prescrições dos vestibulares na seleção dos gêneros. A fundamentação teórica deste estudo foi desenvolvida a partir da leitura de estudiosos dos gêneros discursivos como Bronckart (1999), Bakhtin (1997, 2000, 2004) e Dolz, Noverraz e Schneuwly (2004). Como conclusão, apurou-se que, no vestibular da UEM, há uma

\footnotetext{
${ }^{1}$ Mestranda do PPGEL- Programa de Pós-Graduação em Estudos da Linguagem, Universidade Estadual de Londrina. E-mail naahmaira@hotmail.com Profissional de Língua Portuguesa. E-mail elopes@sercomtel.com.br
}

2 Membro do Programa de Pós-Graduação em Estudos da Linguagem (PPGEL-UEL) e do Mestrado
\end{abstract}


priorização de gêneros que se encontram na esfera de circulação jornalística e literária em detrimento de outros, embora os documentos prescritivos preguem, na prática, a valorização de esferas distintas. Os dados emergentes das respostas das professoras reforçam a importância de uma leitura crítica, tanto dos documentos oficiais quanto das prescrições dos manuais didáticos, visando a valorização dos diferentes gêneros e a colaboração para um ensino democrático nas escolas.

PALAVRAS-CHAVE: Gêneros textuais. Vestibular. Prescrições.

RESUMEN: Este trabajo tiene como objetivo investigar la relación entre lo prescrito en los documentos oficiales y lo que se evalúa en el examen de ingreso de la UEM, a fin de observar si existe o no regularidad en los géneros seleccionados para la prueba. Se trata de una investigación cualitativa, en la cual fueron analizadas las preguntas sobre lengua portuguesa y una propuesta de redacción de las ediciones del examen de ingreso de verano de la UEM (2016 y 2017). Posteriormente, se han realizado entrevistas con profesoras de portugués del nivel medio, una de la red pública de enseñanza y otra de la red privada, con el objetivo de verificar si consideran las prescripciones de los exámenes de ingreso en la selección de los géneros. La fundamentación teórica de este estudio se basa en la lectura de los estudios de géneros discursivos como Bronckart (1999), Bakhtin (1997; 2000; 2004) e Dolz e Schneuwly (2004). Como conclusión, se constató que, en el examen de ingreso de la UEM, se da prioridad a los géneros que se encuentran en la esfera de circulación periodística y literaria en detrimento de otros, aunque los documentos prescriptivos procuren, en la práctica, la valoración de distintas esferas. Los dados resultantes de las respuestas de las profesoras refuerzan la importancia de una lectura crítica, tanto de los documentos oficiales como de las prescripciones de los manuales didácticos, buscando la valorización de los diferentes géneros y la colaboración para una enseñanza democrática en las escuelas.

Palabras-clave: Géneros textuales. Examen de ingreso. Prescripciones.

ABSTRACT: This study aims to investigate the relationship between what is prescribed in the official documents and what is charged in the university entrance examination, in order to observe whether or not there is regularity in the genres selected for the test. This is a qualitative research, in which the Portuguese Language issues were analyzed and the proposal to write two editions of the UEM summer university entrance exam (2016 and 2017). Then, interviews were conducted with two Portuguese-speaking high school teachers, one from the public school system and another from the private network, in order to verify if they consider the prescriptions of the vestibular in the selection of genders. The theoretical basis of this study was developed from the reading of scholars of discursive genres such as Bronckart (1999), Bakhtin (1997, 2000, 2004) and Dolz, Noverraz and Schneuwly (2004). As a conclusion, it was found that, in the university entrance examination, there is a prioritization of genres that are in the sphere of journalistic and literary circulation to the detriment of others, although prescriptive documents preach, in practice, the valuation of different spheres. The data emerging from the teachers' responses reinforce the importance of a critical reading of both the official documents and the textbook prescriptions, aiming at valuing the different genres and collaborating for democratic teaching in schools.

KEYWORDS: Textual genres. Entrance exam. Prescriptions. 


\section{Introdução}

Bakhtin (2004, p. 7) defende que a realidade crucial da língua é a interação. $\mathrm{O}$ autor destaca, antes de tudo, a natureza real dos fatos linguísticos. "[...] Bakhtin valoriza justamente a fala, a enunciação, e afirma sua natureza social, não individual: a fala está indissoluvelmente ligada às condições da comunicação" (BAKHTIN, 2004, p. 7). Portanto, é imprescindível que um trabalho profícuo com a linguagem revele os aspectos não verbais dos textos, indo além da dimensão verbal.

Nesse sentido, para trabalhar a língua em sala de aula, é preciso atividades com os gêneros discursivos, os quais, para Bakhtin (1997, p. 280), são tipos relativamente estáveis de enunciado, caracterizados por estilo, conteúdo temático e composição peculiar. Neste artigo, tratamos de "gêneros discursivos" os eventos linguísticos que outros autores como Bronckart (1999, p. 137) e Marcushi (2005, p. 22) designariam, respectivamente, de gêneros de textos/gêneros textuais.

Os gêneros discursivos abrangem uma grande diversidade de tipologias textuais, em situações de interação a serem vivenciadas, com a finalidade de fomentar o saber a partir do emprego real da linguagem. $O$ documento oficial que adota essa mesma perspectiva é o PCNEM (Parâmetros Curriculares Nacionais - Ensino Médio), o qual aponta que "o ato da fala pressupõe uma competência social de utilizar a língua de acordo com as expectativas em jogo. No ato interlocutivo, o contexto verbal relaciona-se com o extraverbal e viceversa". (BRASIL, 2000, p. 6).

Segundo Bakhtin (2000, p. 279), a utilização da língua ocorre em forma de enunciados (escritos e orais), únicos e concretos, que emanam dos integrantes de uma ou de outra esfera da atividade humana. De acordo com o filósofo, qualquer enunciado considerado isoladamente é individual, no entanto, 
cada esfera de utilização da língua elabora os seus tipos relativamente estáveis de enunciados.

Muitas vezes, o termo "gênero discursivo" é empregado de maneira equivocada por aqueles que não o diferenciam dos "tipos textuais". Por isso, é importante esclarecer que a noção de gênero discursivo remete à natureza social das condições de produção de determinado texto, doravante enunciado (os sujeitos, o suporte, a funcionalidade, a finalidade etc.). Quanto à noção de tipos textuais representa o caráter linguístico (temporal, lexical e sintático) de determinada composição textual. Sintetizando, um gênero discursivo pode compreender uma variedade de tipos textuais que, de acordo com Marcushi (2005, p. 22) são conhecidos como: argumentação, narração, descrição, exposição e injunção (instrução).

Bronckart (1999, p. 138) defende que os segmentos constitutivos de um gênero devem ser considerados como tipos linguísticos, ou seja, como formas específicas de semiotização ou de colocação em discurso. 0 autor afirma ainda que elas são formas dependentes do leque dos recursos morfossintáticos de uma língua e, por isso, em número necessariamente limitado.

A riqueza e a diversidade dos gêneros são infinitas, e isso acontece porque a "variedade virtual da atividade humana é inesgotável, e cada esfera dessa atividade comporta um repertório de gêneros do discurso que vai diferenciandose e ampliando-se à medida que a própria esfera se desenvolve e fica mais complexa." (BAKHTIN, 2000, p. 280).

Ainda de acordo com o autor, a diversidade funcional parece tornar os traços comuns a todos os gêneros do discurso abstratos e inoperantes. Para Bakhtin, provavelmente seja esta a explicação para que o problema geral dos gêneros do discurso nunca tenha sido colocado. Por isso, estudaram-se, mais do que tudo, os gêneros literários.

Pautamos o nosso estudo na investigação de duas edições do vestibular de verão da Universidade Estadual de Maringá, observando sua concepção em relação aos gêneros textuais, assim como a sua relação com as prescrições dos 
documentos oficiais da educação nacional: Parâmetros Curriculares Nacionais, as Diretrizes Curriculares do Paraná e Orientações Curriculares do Ensino Médio. Posteriormente, foram realizadas entrevistas com duas professoras de língua portuguesa do ensino médio, uma da rede pública de ensino e outra da rede particular, visando verificar se consideram as prescrições dos vestibulares na seleção dos gêneros a serem ensinados em sala de aula.

Dessa forma, o presente artigo objetiva: (i) levantar os gêneros cobrados nos vestibulares de verão da UEM - Universidade Estadual de Maringá (2016, 2017), bem como a sua frequência nas provas; (ii) investigar se há valorização de determinados gêneros em detrimento de outros e (iii) analisar os métodos utilizados pelos professores para ensinar gêneros, a fim de compreender se consideram ou não as prescrições dos vestibulares e, claro, para verificar se há diferenças nos métodos utilizados de um professor da rede pública de ensino e de um professor da rede particular.

Para auxiliar nesse estudo, nos apoiamos em alguns estudiosos, além dos já citados, buscamos em Netto (1985), Guimarães (1984) e Whitaker (2010), pesquisadores que discorrem sobre o vestibular, bases na compreensão das características e origens dessas provas, além de Creswell (2004) e Gil (2002) para a metodologia desta pesquisa, a qual se classifica como documental com o uso de métodos mistos.

\section{Material e Métodos}

Esta pesquisa é caracterizada como mista, um método que, de acordo com Creswell (2004, p. 35) é uma técnica que emprega estratégias de investigação que envolvem coleta de dados simultânea ou sequencial para melhor entender os problemas de pesquisa. Segundo o autor:

A coleta de dados também envolve a obtenção tanto de informaç̧̃̃es numéricas (por exemplo, em instrumentos) como de informações de texto (por exemplo, em entrevistas), de forma que o banco de dados 
final represente tanto informações quantitativas como qualitativas. (CRESWELL, 2004, p. 35).

A pesquisa mista utiliza informações documentais, dados quantitativos e submete todos esses dados a uma análise qualitativa. Sendo assim, em um primeiro momento, foi realizada uma análise documental (GIL, 2002), considerando que parte da nossa base teórica conta com leitura e análise de documentos prescritivos, a saber, o PCN e as DCE-PR. Além desses documentos, procedemos a uma breve discussão sobre o histórico do vestibular. Foi discutida ainda uma rápida apresentação da história da Universidade Estadual de Maringá, universidade responsável pela elaboração dos vestibulares analisados no presente trabalho.

Nossas observações a respeito dos documentos prescritivos foram apresentadas, bem como suas relações com estudiosos que se dedicam ao estudo dos gêneros, tais como Mikhail Bakhtin, Bernard Schneuwly, Joaquim Dolz, entre outros, uma vez que esses documentos oficiais são baseados, ao menos em partes, nesses pesquisadores. Considerando também de extrema relevância compreender a noção de gênero, buscamos tais autores para melhor compreensão do que é um gênero e como ele se apresenta em nossa sociedade.

Com o apoio da base teórica foi possível investigar quais são os gêneros cobrados no vestibular da UEM e a frequência deles nas duas edições, sendo elas a de 2016 e a de 2017. Além disso, com o intuito de analisar se as prescrições dos manuais do candidato são estudadas pelos professores de ensino médio, foram realizadas entrevistas com duas professoras, uma da rede pública de ensino e outra da rede particular.

Esses resultados nos permitirão fazer um comparativo no que se refere à variedade de gêneros cobrados nesse exame, além de concluir se as prescrições elaboradas para a realização do mesmo são ou não levadas a sério pelos educadores.

\section{O Vestibular no Brasil e na UEM}


De acordo com Whitaker (2010, p. 291), a origem do vestibular, no Brasil, remonta a 1910, quando foram criados os exames de admissão ao ensino superior no Brasil, que receberiam o título de Exames Vestibulares, em 1915, pela Reforma Carlos Maximiliano. Foi, portanto, entre 1910 e 1915 que muitos acontecimentos e mudanças marcaram a criação do vestibular.

O objetivo dos vestibulares é avaliar as capacidades de linguagem dos estudantes, "e para realizar essa macro ação é preciso que o leitor do texto siga um plano de comandos explicitado verbalmente, desenvolvendo, assim, uma série de micro ações referentes à resolução das situações-problema. (ZIRONDI; NASCIMENTO, 2006, p. 306). Ainda segundo as autoras, o agente-produtor do texto da Prova arquiteta "fazer agir" seu destinatário em determinada direção por meio dos enunciados de comando (ZIRONDI; NASCIMENTO, 2006, p. 312).

Netto (1985, p. 41) explica que o exame de admissão (nome das primeiras provas de vestibular) encontrava-se definido no Decreto 8.659, também de 5 de abril de 1911, que aprovava a Lei Orgânica do Ensino Superior e do Fundamental na República. $O$ art. 65 deste decreto estabelecia que o candidato passasse por um exame que "habilite a um juízo de conjunto sobre o seu desenvolvimento intelectual e capacidade para empreender eficazmente o estudo das matérias que constituem o ensino da faculdade" (BRASIL, 1911).

O autor afirma ainda que a preocupação principal era a de "uma avaliação global do desenvolvimento intelectual do candidato e de uma aferição da sua capacidade para empreender estudos em nível superior sem vinculação a carreira ou cursos específicos".

Segundo Guimarães (1984 apud WHITAKER, 2010, p. 291) não demorou muito tempo para que a quantidade de candidatos ao ensino superior ultrapassasse a quantidade de vagas. Isso ocorreu na década de 1920 e foi então que o vestibular passou a ser como conhecemos hoje, obrigatório a todos que desejam cursar o ensino superior. 
Para Whitaker (2010, p. 292), foram criadas universidades de todos os modelos por todo o território nacional, sendo que a maioria delas a partir do sistema particular de ensino. No entanto, ainda havia muitas a partir do governo federal, interessado na modernização de um país que se urbanizava de forma explosiva.

Nesse contexto surgiu a Universidade Estadual de Maringá, localizada no Noroeste do Paraná. Sua autorização de criação data de 1969, por meio da pela Lei no 6.034 , de 6/11/1969. A UEM, é uma universidade pública, mantida pelo Estado do Paraná e subordinada à Secretaria de Estado da Ciência, Tecnologia e Ensino Superior - SETI, que atrai muitas pessoas de várias cidades do estado e do país interessadas em cursar o ensino superior. Dentre os processos seletivos promovidos pela UEM, o vestibular é o mais concorrido e o mais importante para os candidatos que almejam uma vaga. (UNIVERSIDADE ESTADUAL DE MARINGÁ, 2018b).

Atualmente a universidade realiza dois vestibulares ao ano, Verão e Inverno, mas ambos aprovam para a matrícula no início do ano. O vestibular acontece em 3 dias. No primeiro dia é aplicado um exame de Conhecimentos Gerais contendo 40 questões de alternativas múltiplas elaboradas na perspectiva interdisciplinar envolvendo conteúdos de Física, Filosofia, Artes, Biologia, Geografia, Sociologia, Matemática, História e Química. No segundo dia é aplicada a prova de Língua Portuguesa e Literatura com 15 questões, Língua Estrangeira contendo 5 questões e Redação (de 2 a 4 gêneros textuais). E, por fim, no terceiro dia a prova contém 40 questões de alternativas múltiplas referentes a duas matérias nas áreas de Conhecimentos Específicos. (UNIVERSIDADE ESTADUAL DE MARINGÁ, 2018a).

\section{Aspectos Teóricos: os Gêneros Textuais na Visão dos Documentos Oficiais e dos Estudiosos}


Há muitos documentos prescritivos que regem a educação nacional e estadual do Brasil. Este trabalho foca em três deles: os Parâmetros Curriculares Nacionais (PCNs), as Diretrizes Curriculares Estaduais do Paraná (DCE-PR) e as Orientações Curriculares para o Ensino Médio (OCEM). Nosso propósito é identificar como a disciplina de língua portuguesa é trabalhada em tais documentos buscando relações entre o que é prescrito e o que é realmente cobrado nos vestibulares.

Os documentos prescritivos analisados apresentam um viés sociointeracionista e reforçam a importância de se trabalhar com os gêneros em sala de aula. Dessa forma, pode-se afirmar que tanto os PCNs quanto as DCEs se amparam, pelo menos em parte, na teoria dos gêneros do discurso de Bakhtin (1992). ${ }^{3}$

Os PCNs, de acordo com informações no site do INEP - Instituto Nacional de Estudos e Pesquisas Educacionais Anísio Teixeira ( 2011), "foram elaborados para difundir os princípios da reforma curricular e orientar os professores na busca de novas abordagens e metodologias", esse documento foca o ensino fundamental (ciclos 1 e 2).

Seguindo a mesma ideia, os PCNEM (Parâmetros Curriculares Nacionais Ensino Médio) de língua portuguesa defendem que

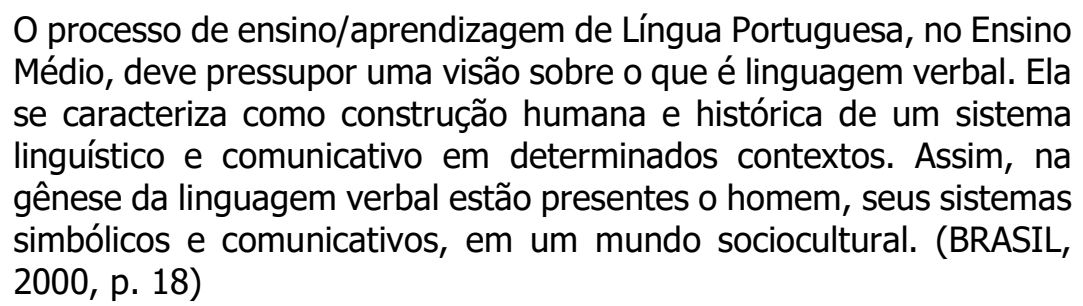

Para o professor de língua materna, de acordo com os PCNEM, essa linguagem verbal é um instrumento de trabalho com caráter sociointeracionista. Esse documento prescritivo defende ainda que 0 processo de ensino/aprendizagem de Língua Portuguesa deve ser baseado em propostas

\footnotetext{
${ }^{3}$ Publicação original datada em 1979.
} 
interativas língua/linguagem, consideradas em um processo discursivo de construção do pensamento simbólico, constitutivo de cada aluno em particular e da sociedade em geral.

No PCN+ (Parâmetros Curriculares Nacionais do EM: orientações educacionais complementares aos PCNs), constata-se que o "texto verbal pode assumir diferentes feições, conforme a abordagem temática, a estrutura composicional, os traços estilísticos do autor - conjunto que constitui o conceito de gênero textual." (BRASIL, 2002, p. 60). Dessa forma, conclui-se que o trabalho com textos deve ser associado aos gêneros, pois como Rojo (2000, p. 35) afirma "as práticas de leitura/escrita de textos e de produção de textos orais e escritos estariam integradas na abordagem do texto como unidade de ensino para a construção do gênero como objeto de ensino [...]".

Portanto, o trabalho com textos e, consequentemente, com os gêneros, permite ao estudante um ensino que, conforme aponta o documento orientador do PCNEM, abandona:

[...] o tradicional esquema das estruturas textuais (narração, descrição, dissertação) para adotar a perspectiva de que a escola deve incorporar em sua prática os gêneros, ficcionais ou não ficcionais, que circulam socialmente: na literatura, o poema, o conto, o romance, o texto dramático, entre outros; no jornalismo, a nota, a notícia, a reportagem, o artigo de opinião, o editorial, a carta do leitor; nas ciências, o texto expositivo, o verbete, o ensaio; na publicidade, a propaganda institucional, o anúncio; no direito, as leis, os estatutos, as declarações de direitos, entre outros. (BRASIL, 2000, p. 77).

Com ideias semelhantes, as DCEs do Paraná, publicadas em 2008, defendem que:

O ensino-aprendizagem de Língua Portuguesa visa aprimorar os conhecimentos linguísticos e discursivos dos alunos, para que eles possam compreender os discursos que os cercam e terem condições de interagir com esses discursos. Para isso, é relevante que a língua seja percebida como uma arena em que diversas vozes sociais se defrontam, manifestando diferentes opiniões. (PARANÁ, 2008, p. 50) 
Dessa maneira, é preciso que os educadores promovam o letramento dos alunos por meio da diversidade de textos e suas funções sociais. Assim, eles se envolverão nas práticas de uso da língua em todos os eixos (escrita, leitura e oralidade). Diante disso, o conceito de texto também deve ser ampliado, o qual envolve não apenas a formalização do discurso verbal ou não verbal, mas o evento que abrange o antes, isto é, as condições de produção e elaboração; e 0 depois, ou seja, a leitura ou a resposta ativa. Afinal, como o documento afirma citando Bakhtin (1999), "o texto ocorre em interação e, por isso mesmo, não é compreendido apenas em seus limites formais" (PARANÁ, 2008, p. 51).

Quanto às Orientações Curriculares para Ensino Médio (BRASIL, 2006), trata-se de um documento que possui três volumes, os quais representam as áreas do conhecimento. Neste trabalho, utilizamos apenas o volume 1 que aborda a área de Linguagens, códigos e tecnologia. O propósito das OCEM é contribuir para o diálogo entre instituição de ensino e professor sobre a prática docente. 0 documento defende que se deve considerar uma "reflexão sobre os gêneros literários e outros gêneros, sobre a linguagem literária e as outras linguagens, entre outras relações possíveis" (BRASIL, 2006, p. 73).

Após as leituras desses documentos prescritivos, é possível concluir que todos consideram de grande relevância o trabalho com uma variedade de gêneros em sala de aula. As diretrizes postulam que "o aperfeiçoamento da escrita se faz a partir da produção de diferentes gêneros" (PARANÁ, 2008, p. 56), enquanto os parâmetros defendem o quão importante é para o estudante saber analisar as particularidades sem perder a visão do todo, pois assim ele percebe que tais especificidades têm um sentido socialmente construído, e desta forma, "o estudo dos gêneros discursivos e dos modos como se articulam proporciona uma visão ampla das possibilidades de usos da linguagem." (BRASIL, 2000, p. 8).

Os documentos legais que regem a educação nacional e estadual, ao adotarem a perspectiva dos gêneros como a forma mais adequada de se trabalhar os conteúdos da disciplina de LP, influenciam o trabalho realizado tanto 
nas escolas da rede pública de ensino quanto nas escolas da rede particular. Por esse motivo, é imprescindível saber se há uma sintonia entre o que é cobrado nos vestibulares e o que é prescrito nos documentos oficiais, além de compreender se tais prescrições são estudadas e consideradas pelo professor no ensino de gêneros.

Sabe-se que os documentos oficiais adotam o texto como unidade de ensino e os gêneros como objeto mediador no processo de ensino-aprendizagem. Sendo assim, torna-se pertinente tratar desse assunto um pouco mais a fundo.

De acordo com Nascimento e Barros (2007, p. 1), as discussões a respeito da noção de gênero (textual ou discursivo) vêm sendo feitas pelos estudiosos da área de ensino de línguas há muito tempo. Para as autoras:

Tal conceito tem ajudado vários pesquisadores (de correntes teóricas diversas) a compreender as interações sociais nas múltiplas esferas em que agem pela linguagem. Assim, 0 conceito de gênero, tradicionalmente abordado pela Literatura e Retórica, passa a assumir, principalmente com base nos estudos de Mikhail Bakhtin, um elo entre o uso da língua na sua forma "natural", o seja, inserida num contexto sócio-histórico, onde se confrontam as construções econômicas, semióticas e culturais produzidas ao longo da história da humanidade e as práticas de linguagem escolarizadas, confinadas às quatro paredes da sala de aula. (NASCIMENTO; BARROS, 2007, p. 1).

As autoras, citando Bakhtin (1992 apud NASCIMENTO; BARROS, 2007, p. 7), afirmam que "os gêneros não só "regulam", organizam, como também significam toda interação humana, são eles que orientam todo ato de linguagem". Isso nos leva a entender que o ser humano, em suas condições mentais e físicas desenvolvidas, está sempre fazendo uso de gêneros da linguagem para a comunicação humana, seja ela escrita, seja verbal.

Dolz, Noverraz e Schneuwly (2004, p. 74), também apoiando-se em Bakhtin, compreendem os gêneros como "instrumentos que fundam a possibilidade de comunicação". Os instrumentos encontram-se entre o indivíduo que age e o objeto sobre o qual ou a situação na qual ele age: eles determinam seu comportamento, guiam-no, afinam e diferenciam sua percepção da situação na qual ele é levado a agir. (DOLZ; NOVERRAZ; SCHNEUWLY, 2004, p. 23). 
Os autores, ainda seguindo Bakhtin, afirmam que três elementos caracterizam os gêneros: o conteúdo temático, o estilo e a construção composicional. Além disso, defendem que a escolha de um gênero é determinada pela "esfera, as necessidades da temática, o conjunto dos participantes e a vontade enunciativa ou intenção do locutor" (DOLZ; NOVERRAZ; SCHNEUWLY, 2004, p. 25).

Compreendemos, portanto, a importância de um ensino aliado aos gêneros, e muito além disso, a razão pela qual os documentos prescritivos sugerem o trabalho com eles. Embora seja evidente que nossa forma de comunicação mais usada, a fala, é moldada às formas dos gêneros, vale enfatizar a relevância desse estudo não só nesta pesquisa, como também na sociedade. Citando Bakhtin (1992, p. 302), podemos resumir esse tópico da seguinte maneira:

Aprendemos a moldar nossa fala às formas do gênero e, ao ouvir a fala do outro, sabemos de imediato, bem nas primeiras palavras, pressentirIhe o gênero [...] Se não existissem os gêneros do discurso e se não os dominássemos, se tivéssemos de criá-los pela primeira vez no processo da fala, se tivéssemos de construir cada um de nossos enunciados, a comunicação verbal seria quase impossível. (BAKHTIN, 1992, p. 302).

Corroborando com tais propósitos do ensino de língua, Bakhtin e Volochinov (2004, p. 125) afirmam que a verdadeira substância da língua não é constituída por um sistema abstrato de formas linguísticas nem pela enunciação monológica isolada, nem pelo ato psicofisiológico de sua produção, mas pelo fenômeno social da interação verbal, realizada por meio da enunciação ou das enunciações $A$ interação verbal constitui assim a realidade fundamental da língua.

É por meio do domínio da linguagem que as estruturas mentais são elevadas, desenvolvendo conceitos espontâneos, a priori, que, a partir de um processo de ensino sistematizado e organizado, se transforma em conhecimentos científicos. Então, compreendendo essas formas de apropriação da linguagem, assume-se uma concepção de língua social, interativa e histórica, constituída da materialidade das situações empíricas do dia a dia dos indivíduos, ou seja, uma 
língua real, que existe a partir das práticas discursivas, que é concretizada em textos orais e escritos, os quais são chamados de gêneros discursivos.

Desta forma, compreendendo a relevância dos gêneros e do domínio dos falantes sobre eles torna-se fácil visualizar a importância de sua abordagem em vestibulares, de modo que se os gêneros são utilizados durante todo o tempo pelos falantes e se estão presentes em todas as esferas da sociedade, o trabalho com eles em sala de aula deveria ser cotidiano.

\section{Resultados e Discussão}

A presente análise teve como objeto de pesquisa um total de 30 questões de Língua Portuguesa, sendo 15 no vestibular de verão da Universidade Estadual de Maringá de 2016 e 15 no de 2017, além das duas propostas de redação. Foram analisados ainda dois questionários com 5 questões cada, os quais foram respondidos por duas professoras de LP, uma da rede pública de ensino e a outra da rede particular.

Inicialmente, foi realizada uma divisão das questões, das quais separamos as que cobravam um conhecimento linguístico da língua e as que tratavam de aspectos de leitura, sejam eles literários ou não. 
Gráfico 1 - Prevalência de questões - Vestibular 2016

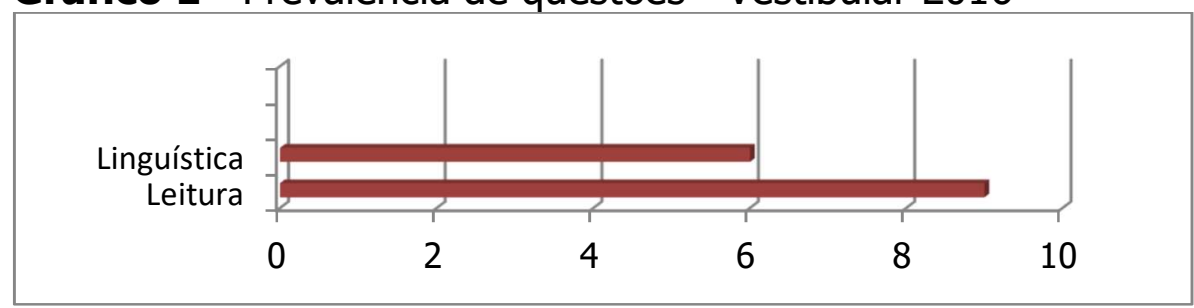

Fonte: Universidade Estadual de Maringá (2016).

Gráfico 2 - Prevalência de questões - Vestibular 2017

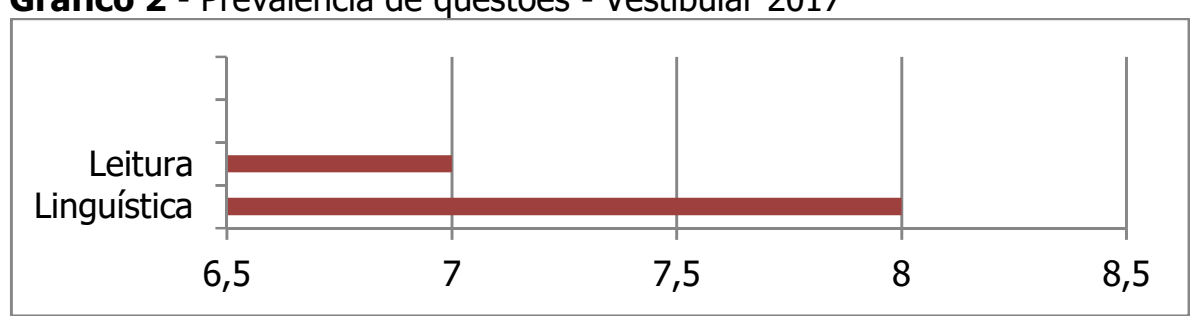

Fonte: Universidade Estadual de Maringá (2017).

O gráfico 1 engloba as questões referentes ao vestibular de 2016. Observa-se que apenas 6 questões tratam dos aspectos linguísticos, ou seja, cobram o conhecimento de características estruturais, morfológicas e sintáticas da língua, enquanto as outras 9 exigem uma compreensão semântica dos textos presentes na prova. Em contrapartida, o gráfico 2, referente às questões do vestibular do ano de 2017, revela dados muito distintos. São 8 questões que abordam aspectos linguísticos e 7 de leitura. Nota-se, portanto, que há, no vestibular de 2017, mais questões que tratam de características estruturais, morfológicas e sintáticas do que questões que exigem compreensão semântica a partir de uma leitura atenta dos textos.

Posteriormente, observamos as questões de leitura, maioria no vestibular de 2016. Analisamos separadamente cada uma dessas questões visando identificar quantas pertencem aos gêneros primários e aos gêneros secundários que, segundo a concepção de Bakhtin (1997, p. 282), são classificados da seguinte maneira: 
Os gêneros secundários do discurso - o romance, o teatro, o discurso científico, o discurso ideológico, etc. - aparecem em circunstâncias de uma comunicação cultural, mais complexa e relativamente mais evoluída, principalmente escrita: artística, cientifica sociopolítica. Durante o processo de sua formação, esses gêneros secundários absorvem e transmutam os gêneros primários (simples) de todas as espécies, que se constituíram em circunstâncias de uma comunicação verbal espontânea. (BAKHTIN, 1997, p. 282).

Analisando as duas edições do vestibular da UEM, é possível concluir que todas as questões são compostas por gêneros secundários. Julgamos esse dado esperado, já que uma vez que o nosso objeto de análise se trata de um processo seletivo de extrema relevância, seria incomum a presença de gêneros primários simples e de "comunicação verbal espontânea" (BAKHTIN, 1997, p. 281).

Por fim, considerando que todas as questões de leitura pertencem aos gêneros secundários, buscamos identificar quais são esses gêneros de modo a constatar se há a valorização de determinados gêneros em detrimento de outros nos vestibulares de 2016 e de 2017 da UEM para, posteriormente, compararmos esses resultados.

Dolz, Noverraz e Scheneuwly (2004, p. 25) afirmam que cada esfera de troca social elabora tipos relativamente estáveis de enunciados: os gêneros, assim, os autores defendem que "a escolha de um gênero se determina pela esfera". Partindo desse pressuposto, foram elencadas algumas esferas visando determinar quais gêneros estão presentes nas duas provas analisadas. As esferas definidas foram: esfera literária, esfera cotidiana, esfera jornalística, esfera publicitária, esfera religiosa, esfera instrucional, esfera científica, esfera artísticocultural, esfera escolar e esfera burocrática.

Analisando as duas provas, conclui-se que há uma predominância de questões pertencentes à esfera jornalística e da esfera literária. Em ambas, 10 questões são elaboradas a partir de uma notícia e 5 questões possuem gêneros da esfera literária. Faz-se necessário ressaltar que grande parte das 10 questões referentes à esfera jornalística abordam conhecimentos de características estruturais, morfológicas e sintáticas da língua. Esses dados sugerem que não há uma variedade de gêneros nos vestibulares de 2016 e de 2017 da UEM. 
Desta forma, elencamos abaixo a listagem de quais gêneros, e não tipos textuais, estão presentes nas edições do vestibular de 2016 e 2017, respectivamente.

Tabela 1 - Gêneros presentes nas provas de 2016/2017 e sua ocorrência

\begin{tabular}{c|cc}
\hline \multicolumn{3}{c}{ Vestibular de 2016 } \\
\hline Gêneros & Ocorrência \\
\hline \multicolumn{2}{|c|}{ Reportagem } & 10 \\
\hline Romance & 3 \\
\hline Poema & \multicolumn{2}{c}{} \\
\hline \multicolumn{2}{c}{ Vestibular de 2017 } \\
\hline Gêneros & Ocorrência \\
\hline Coluna & 10 \\
\hline Romance & 3 \\
\hline Poema & 1 \\
\hline Conto & 1 \\
\hline
\end{tabular}

Fonte: Universidade Estadual de Maringá $(2016,2017)$.

Na tabela 1, observa-se que, no vestibular de 2016, houve maior número dos gêneros Reportagem e Romance, enquanto no vestibular de 2017 houve maior número dos gêneros Coluna e Romance. É importante ressaltar que os gêneros Reportagem e Coluna são utilizados para responder a 10 questões. Ambas as provas dividem-se em Língua Portuguesa e Literaturas em Língua Portuguesa, sendo 10 questões para a primeira parte e 5 questões para a segunda. Na primeira parte da prova, há um texto da esfera jornalística sobre o qual são realizadas 10 perguntas, em sua maioria sobre questões estruturais da língua. Na segunda parte, há o predomínio dos gêneros da esfera literária: romance, poema e conto.

Analisando as provas, conclui-se que nas duas edições a intenção de variedade de gêneros, conforme preveem os PCN, as DCE e as OCEM, não existe. A maioria deles é pertencente à esfera jornalística e à esfera literária. Em contrapartida, na prova de redação, a Universidade Estadual de Maringá exige a escrita de alguns gêneros textuais, deixando no passado a dissertação, tradicionalmente solicitada nas escolas e em grande parte dos vestibulares. 
O Manual do Candidato ao vestibular da Universidade Estadual de Maringá (2016) apresenta algumas orientações gerais para a prova de língua portuguesa, na qual está inserida a questão de redação, conforme se pode ler:

\begin{abstract}
A prova de Redação exige do candidato a produção de dois a quatro textos em determinados gêneros textuais. A lista dos gêneros textuais é divulgada com antecedência e, periodicamente, sofre mudança, mantendo parte dos gêneros textuais solicitados. A prova de redação é o principal instrumento de avaliação da capacidade de pensar, de compreender e de expressar-se por escrito sobre um determinado assunto, além de avaliar o domínio e o conhecimento dos mecanismos da língua culta. A seguir, apresenta-se a lista dos gêneros textuais que poderão ser solicitados para a produção da redação neste vestibular. 1 Artigo de opinião. 2 Carta aberta. 3 Carta de reclamação. 4 Carta de solicitação. 5 Carta do leitor. 6 Relato. 7 Resposta argumentativa. 8 Resposta interpretativa. 9 Resumo. 10 Texto instrucional. (UNIVERSIDADE ESTADUAL DE MARINGÁ, 2016, p. 38).
\end{abstract}

Conclui-se, portanto, que o manual sinaliza uma nova proposta de escrita, ancorada em situações de comunicação precisas com a solicitação da escrita de gêneros textuais. Ou seja, muito diferente das propostas que tradicionalmente ainda são apresentadas em alguns vestibulares, pautadas na indicação de texto dissertativo-argumentativo.

Analisando a prova de redação do vestibular de 2016 e de 2017, nota-se a apresentação de uma proposta de texto baseada no uso contextualizado da escrita, já que contempla dois gêneros textuais que circulam na sociedade. No vestibular de 2016, os gêneros são: resposta argumentativa e carta aberta. Na edição de 2017: carta do leitor e texto instrucional. Além disso, é importante ressaltar que foram disponibilizadas informações referentes ao contexto de produção, público-alvo e ambiente de circulação, bem como aos gêneros indicados na prova e ao tema. Confirma-se, então, uma preocupação com a diversidade dos gêneros nas provas de redação dos vestibulares da UEM.

E, a fim de alcançar o nosso terceiro objetivo desta pesquisa, analisamos os métodos utilizados pelos professores para ensinar gêneros, visando compreender se consideram ou não as prescrições dos vestibulares e, claro, para 
verificar se há diferenças nos métodos utilizados de um professor da rede pública de ensino e de um professor da rede particular.

Para tanto, entrevistamos dois professores da cidade de Rolândia-PR, sendo que o primeiro atua na rede pública de ensino e o segundo na rede particular. Analisando as respostas nos questionários ${ }^{4}$, o professor A (rede pública), respondendo à pergunta: "Você utiliza materiais didáticos para escolher os gêneros que serão trabalhados em sala ou utiliza outras referências?', afirmou:

\footnotetext{
Trabalho com materiais intercalados, assim consigo uma maior amplitude em relação aos gêneros, bem como outros conteúdos da matéria. Importante ressaltar que, a boa escolha do livro didático ajuda e se tornar instrumento fundamental na sala de aula.
}

Logo, constatamos, com base nas respostas do professor $\mathrm{A}$, que há um trabalho com a diversidade de gêneros em sala de aula, uma vez que ele afirma "trabalho os gêneros textuais selecionados para a série determinada. No ensino médio, gênero como: Carta, dissertativo - argumentativo, artigos de opinião, enfim estes que vem sendo cobrado pelas universidades". No entanto, percebese que o professor não considera as prescrições dos vestibulares para fazer a escolha dos gêneros a serem ensinados em aula, pois não as cita em momento algum durante a entrevista.

Em contrapartida, a resposta do professor B (rede particular) para a pergunta "Você utiliza materiais didáticos para escolher os gêneros que serão trabalhados em sala ou utiliza outras referências?', foi:

Não. Os materiais são preparados de acordo com as necessidades dos alunos e com o desenvolvimento deles. Além desses fatores, os temas escolhidos são sempre atuais e os gêneros escolhidos focados nos vestibulares almejados por eles, seguindo sempre o que ditam os manuais e editais disponibilizados pelas faculdades.

\footnotetext{
${ }^{4}$ Em anexo.
} 
O professor da rede particular, portanto, utiliza os manuais do candidato para preparar suas aulas sobre os gêneros. Segundo ele, é importante "trabalhar os conteúdos focando na maneira como eles são cobrados nas questões dos vestibulares. As teorias e as atividades são direcionadas em sala para que se sintam familiarizados e preparados no dia da prova'. Levando em consideração todas as afirmações de ambos os professores, concluímos que há diferenças nos métodos utilizados de um professor da rede pública de ensino e de um professor da rede particular. É justamente devido a essas diferenças que temos presenciado tantas notas altas nos vestibulares de alunos que estudaram em uma escola particular, quando comparado às notas dos alunos da rede pública de ensino.

Como postulam Nascimento e Grande (2018), o agir representado por professores pode apontar indícios de conflitos por eles vivenciados ao se depararem com demandas por inovação em contraste com os saberes e objetos didatizados nas salas de aula em anos de exercício profissional. Ainda que se observe uma certa nebulosidade no tratamento que é dado aos gêneros nas provas vestibulares, o exame do vestibular demonstra um movimento de extensão na direção de uma diversificação dos gêneros textuais propostos nas questões da prova. Nesse quadro de incertezas, professores ainda se sentem inseguros diante dos desafios de trabalhar as práticas discursivas das muitas esferas de comunicação, onde são cruciais noções fundamentais que levam à consideração de parâmetros contextuais e mecanismos linguísticos e discursivos que entram em jogo na produção e recepção dos gêneros textuais. Ainda se observam, entre professores, diferenças gritantes nos modos de organizar e implementar transposições didáticas das práticas discursivas materializadas em gêneros textuais.

Diante disso, é importante reforçar a necessidade de seguir o que os documentos prescritivos abordam para que os professores, tanto da rede pública como da rede privada, possam preparar bem seus alunos para a conquista de uma vaga no ensino superior. 
Os gêneros textuais e o vestibular da UEM: entre o que é prescrito nos documentos oficiais e o que é cobrado dos candidatos 


\section{Considerações Finais}

A partir da análise dos enunciados de comando (consignas) que propõem os vestibulares de 2016 e de 2017 da Universidade Estadual de Maringá, notamos que há um predomínio das questões de leitura sobre as de linguística apenas da edição de 2016. Na prova realizada no ano de 2017, as questões de linguística prevaleceram, fato que mostra a importância de uma campanha efetiva para que o ensino não seja completamente voltado para análise gramatical e estrutural. 0 ideal é que os vestibulares busquem abordar o que é estudado em sala de aula, conciliando com o que os documentos oficiais sugerem e priorizando, portanto, as questões de leitura sem deixar de reconhecer a relevância do aspecto linguístico da língua.

Constatamos que a intenção de variedade de gêneros, conforme preveem os PCN, as DCE e as OCEM, não existe na sessão de Língua Portuguesa nas duas edições do vestibular da UEM. A maioria dos gêneros é pertencente à esfera jornalística e à esfera literária. Em contrapartida, na prova de redação, a Universidade Estadual de Maringá exige a escrita de alguns gêneros textuais, deixando no passado a dissertação, tradicionalmente solicitada nas escolas e em grande parte dos vestibulares. Logo, há uma preocupação em abordar os diversos gêneros na redação.

Por fim, considerando as respostas dos professores nas entrevistas realizadas, concluímos que, infelizmente, há diferenças nos métodos que ambos utilizam para ensinar os gêneros em sala de aula. Faz-se necessário, portanto, que não apenas o professor da rede particular de ensino considere os documentos prescritivos para preparar os alunos para o vestibular, e sim que todos os educadores compreendam a importância de se estudar essas prescrições. Da mesma forma, é preciso ainda que os próprios vestibulares sigam as prescrições dos documentos oficiais, sobre os quais falamos neste trabalho.

Em suma, ressaltamos que as duas edições analisadas poderiam englobar uma quantidade maior de gêneros de maneira a abranger mais esferas, em vez 
de prender-se a métodos tradicionais de avaliação. No entanto, é também imprescindível que o ensino nas escolas pactue, na prática, do que indica os documentos prescritivos, preparando o estudante para uma prova com a variedade de gêneros sugerida. Do contrário, mesmo que os vestibulares sejam ricos em gêneros, o aluno não alcançará o seu objetivo se não tiver tido um bom contato escolar com eles.

\section{Referências}

BAKHTIN, Mikhail Mikhailovich. Estética da criação verbal. 4. ed. São Paulo: Martins Fontes, 1997.

BAKHTIN, Mikhail Mikhailovich. Estética da criação verbal. Tradução do francês por Maria Ermantina Galvão G. Pereira. São Paulo: Martins Fontes, 2000.

BAKHTIN, Mikhail Mikhailovich. Os gêneros do discurso. In: BAKHTIN, Mikhail Mikhailovich. Estética da criação verbal. São Paulo: Martins Fontes, 1992. p. 277-326.

BAKHTIN, Mikhail Mikhailovich; VOLOSHINOV, Valentin Nikolaevich. Marxismo e filosofia da linguagem: problemas fundamentais do método sociológico na ciência da linguagem. São Paulo: Hucitec, 2004.

BRASIL. Câmara dos Deputados. Decreto no 8.659, de 5 de abril de 1911. Approva a lei Organica do Ensino Superior e do Fundamental na República. Brasília: Câmara dos Deputados, 1911. Disponível em: https://www2.camara.leg.br/legin/fed/decret/1910-1919/decreto-8659-5-abril1911-517247-publicacaooriginal-1-pe.html. Acesso em: 24 maio 2019.

BRASIL. Ministério da Educação e do Desporto. Secretaria da Educação Básica. $P C N+$ : orientações educacionais complementares aos parâmetros curriculares nacionais. Brasília: MEC, 2002. Disponível em:

http://portal.mec.gov.br/seb/arquivos/pdf/linguagens02.pdf. Acesso em: 6 ago. 2018.

BRASIL. Ministério da Educação e do Desporto. Secretaria da Educação Básica. Orientações curriculares para o ensino médio: linguagens, códigos e suas tecnologias. Brasília: MEC, 2006. Disponível em: http://portal.mec.gov.br/seb/arquivos/pdf/book_volume_01_internet.pdf. Acesso em: 6 ago. 2018. 
BRASIL. Ministério da Educação e do Desporto. Secretaria de Educação Básica. Parâmetros curriculares nacionais. Brasília: MEC, 2000. Disponível em: http://portal.mec.gov.br/seb/arquivos/pdf/14_24.pdf. Acesso em: 5 ago. 2018.

BRONCKART, Jean-Paul. Atividade de linguagem, textos e discurso: por um interacionismo sociodiscursivo. Tradução de Anna Rachel Machado e Éricles Cunha. São Paulo: EDUC, 1999.

CRESWELL, John W. Projeto de pesquisa: métodos qualitativo, quantitativo e misto. Porto Alegre: Artmed, 2004.

DOLZ, Joaquim; NOVERRAZ, Michele; SCHNEUWLY, Bernanrd. Sequências didáticas para o oral e a escrita: apresentação de um procedimento. In: SCHNEUWLY, Bernard; DOLZ, Joaquim. Gêneros orais e escritos na escola. Tradução de Roxane Rojo e Glaís Sales Cordeiro. Campinas: Mercado das Letras, 2004.

GIL, Antônio Carlos. Como elaborar projetos de pesquisa. São Paulo: Atlas, 2002.

GUIMARÃES, Sonia. Como se faz a indústria do vestibular. Petrópolis, RJ: Vozes, 1984.

INSTITUTO NACIONAL DE ESTUDOS E PESQUISAS ANÍSIO TEIXEIRA - INEP. Parâmetros Curriculares Nacionais. Brasília, DF: INEP, 2011. Disponível em: smeduquedecaxias.rj.gov.br/nead/...inep.../parametros-curricularesnacionais.html. Acesso em: 1 ago. 2015.

MARCUSCHI, Luiz Antônio. Gêneros textuais: definição e funcionalidade. In: DIONÍSIO, Ấngela Paiva; MACHADO, Anna Rachel; BEZERRA, Maria Auxiliadora (org.). Gêneros textuais \& ensino. 4. ed. Rio de Janeiro: Lucerna, 2005.

NASCIMENTO, Elvira Lopes; BARROS, Eliana Merlin Deganutti. Gêneros textuais e livro didático: da teoria à prática. Linguagem em (Dis)curso, Tubarão, v. 7, n. 2, p. 241-270, maio/ago. 2007.

NASCIMENTO, Elvira Lopes; GRANDE, Paula Baracat. Identidades docentes entre mundos discursivos em disputa: formação do professor, letramentos e desenvolvimento. Trabalhos em Linguística Aplicada, Campinas, v. 57, p. 243264, 2018.

NETTO, Adolpho Ribeiro. O vestibular ao longo do tempo: implicações e implicâncias. In: SEMINÁRIO VESTIBULAR HOJE, 1985, Brasília. Anais [...]. Brasília: MEC, 1985. Disponível em: http://www.fcc.org.br/pesquisa/publicacoes/es/artigos/116.pdf. Acesso em: 1 ago. 2015. 
PARANÁ. Secretaria de Estado da Educação. Diretrizes curriculares da educação básica língua portuguesa. Curitiba: SEE, 2008. Disponível em: http://www.educadores.diaadia.pr.gov.br/arquivos/File/diretrizes/dce_port.pdf. Acesso em: 1 ago. 2015.

UNIVERSIDADE ESTADUAL DE MARINGÁ. Comissão do Vestibular Unificado. Disponível em: Vestibular de verão 2017. Maringá: UEM, 2017. Disponível em: http://www.cvu.uem.br/. Acesso em: 5 ago. 2018.

UNIVERSIDADE ESTADUAL DE MARINGÁ. Comissão do Vestibular Unificado. Disponível em: Vestibular EAD 2016. Maringá: UEM, 2016. Disponível em: http://www.cvu.uem.br/. Acesso em: 5 ago. 2018.

UNIVERSIDADE ESTADUAL DE MARINGÁ. Comissão do Vestibular Unificado. Composição e valoração das provas. Maringá: UEM, 2018a. Disponível em: http://www.cvu.uem.br/composicaoprovas.html. Acesso em: 5 ago. 2018.

UNIVERSIDADE ESTADUAL DE MARINGÁ. Histórico. Maringá: UEM, 2018b. Disponível em: http://www.uem.br/sobre-a-uem/historico. Acesso em: 1 ago. 2018.

WHITAKER, Dulce Consuelo Andreatta. Da "invenção" do vestibular aos cursinhos populares: um desafio para a orientação profissional. Revista Brasileira de Orientação Profissional, São Paulo, v. 11, n. 2, dez. 2010. Disponível em:

http://pepsic.bvsalud.org/scielo.php?script=sci_arttext\&pid=S167933902010000200013. Acesso em: 1 ago. 2018.

ZIRONDI, Maria Ilza; NASCIMENTO, Elvira Lopes. Os enunciados de comando da prova do ENEM e sua relação com competências e capacidades para a resolução de situaç̃ões-problema. Signum: Estudos de Linguagem, Londrina, v. 9, p. 289-315, 2006. 
Anexo 1

\section{Questionário}

Nome: Jackeline Rodrigues de Sales Borges (Professora da Rede Pública de Ensino)

Data de nascimento: 24/09/1991

Cidade: Rolândia-PR.

1. Professor (a), quais são os métodos que você utiliza para preparar o seu aluno para o vestibular?

R. Os métodos utilizados são os mais diversificados possível, pois sabemos das diferenças possibilidade de aprendizagem, sendo ela oral, escrita, bem como não- verbal. Utilizo aulas expositivas, pesquisas, análise de material específico da disciplina, entre outros.

2. Sabe-se que a prova de redação exige do estudante a produção de textos em determinados gêneros textuais. De que forma você trabalha os gêneros e o que você leva em consideração no momento de preparar as aulas sobre esse tema?

R. O conhecimento sobre gêneros textuais são fundamentais para que 0 aluno consiga realizar uma boa prova de vestibular, sobretudo uma redação. Trabalho os gêneros textuais selecionados para a série determinado, ou seja, cada série estuda um gênero específico. No ensino médio, gênero como: Carta, dissertativo - argumentativo, artigos de opinião, enfim estes que vem sendo cobrado pelas universidades. Realizamos leitura do gênero, sua estrutura e conteúdo, por fim realizamos a produção textual e possíveis Refacções.

3. As propostas de redação dos vestibulares são sempre muito aguardadas. Professores e vestibulandos geralmente discutem as possibilidades de tema. Mas e quanto ao gênero? A dissertação ainda é mantida como uma das principais propostas ou o cenário mudou? De que forma você acompanha essas notícias? 
R. Busco muito a ajuda da Internet neste caso. Páginas de redes sociais ligadas a vestibulares, disponibilizam vários artigos discutindo esse tema, de qual gênero possivelmente ainda está em alta. Vejo mudanças, algumas universidades já priorizam outros gêneros, entretanto a dissertação ainda é a mais cobrada, pelo menos em nossa região do Estado do Paraná.

4. Conhecer gêneros diversos é importante para o vestibular? Por quê?

R. Importante para o vestibular e importante para qualquer indivíduo que deseja exercer e desempenhar um papel na sociedade. É através dos gêneros textuais que eu entendo e me faço entender, produzindo e interpretando textos ao longo do dia. Textos esses verbais ou não - verbais.

5. Você utiliza materiais didáticos para escolher os gêneros que serão trabalhados em sala ou utiliza outras referências?

R. Em relação a material didático, é muito relativo, pois depende da escola que você está atuando. Algumas o uso é obrigatório, outras não. Independente dos casos, Trabalho com materiais intercalados, assim consigo uma maior amplitude em relação aos gêneros, bem como outros conteúdos da matéria. Importante ressaltar que, a boa escolha do livro didático ajuda e se tornar instrumento fundamental na sala de aula.

Anexo 2

\section{Questionário}

Nome: Jennifer Morilia Manarin Rodrigues (Professora da Rede Particular de Ensino)

Data de nascimento: 18.03 .1982

Cidade: Rolândia-PR.

1. Professor (a), quais são os métodos que você utiliza para preparar o seu aluno para o vestibular? 
R. Procuro trabalhar os conteúdos focando na maneira como eles são cobrados nas questões dos vestibulares. As teorias e as atividades são direcionadas em sala para que se sintam familiarizados e preparados no dia da prova.

2. Sabe-se que a prova de redação exige do estudante a produção de textos em determinados gêneros textuais. De que forma você trabalha os gêneros e o que você leva em consideração no momento de preparar as aulas sobre esse tema?

R. Na verdade, trabalho mais com tipologias que com gêneros. Penso que um aluno que sabe construir uma argumentação, formular senso crítico e se expressar consegue desenvolver qualquer texto/gênero. Além disso, os temas atuais e relevantes permeiam os debates pré-escrita.

3. As propostas de redação dos vestibulares são sempre muito aguardadas. Professores e vestibulandos geralmente discutem as possibilidades de tema. Mas e quanto ao gênero? A dissertação ainda é mantida como uma das principais propostas ou o cenário mudou? De que forma você acompanha essas notícias?

R. A dissertação ainda é muito importante devido ao foco de alguns alunos no ENEM. No entanto, o público com que trabalho tem alguns vestibulares já determinados como foco, os quais pouco cobram a estrutura da dissertação.

4. Conhecer gêneros diversos é importante para o vestibular? Por quê?

R. É importante saber escrever! O aluno precisa de ter habilidade com a articulação da linguagem de firma crítica. Após desenvolver essa habilidade, ele precisa saber os gêneros que são cobrados nas universidades que ele pretende prestar o vestibular.

5. Você utiliza materiais didáticos para escolher os gêneros que serão trabalhados em sala ou utiliza outras referências?

R. Não. Os materiais são preparados de acordo com as necessidades dos alunos e com o desenvolvimento deles. Além desses fatores, os temas escolhidos são sempre atuais e os gêneros escolhidos focados nos vestibulares almejados 
por eles, seguindo sempre o que ditam os manuais e editais disponibilizados pelas faculdades. 